Jalan Teuku Umar, Lubuk Baja, Kota Batam-Indonesia Telp. 0778 - 4083113

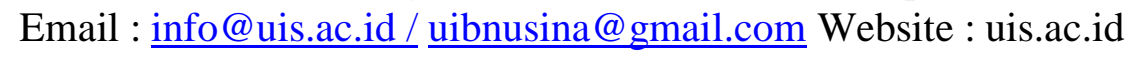

\title{
PENGARUH PEMBERIAN INSENTIF, SEMANGAT KERJA, BEBAN KERJA DAN STRES KERJA TERHADAP LOYALITAS PEGAWAI PADA KANTOR KECAMATAN BATAM KOTA, KOTA BATAM
}

\author{
Sumardin $^{1}$,Haji Mustaqim ${ }^{2}$, Sabri $^{3}$ \\ Manajemen, Fakultas Ekonomi dan Bisinis, Universitas Ibnu Sina \\ Email; sumardinibnusina@gmail.com
}

\begin{abstract}
This study aims to determine the effect of Work Incentives, Work Spirit, Workload and Work Stress on Employee Loyalty at the Head Office of Batam City, Batam. This study uses a quantitative approach using a survey method. Quantitative analysis is used to analyze the collected data. The population in this study were all employees at the Head Office of Batam City, Batam, totaling 70 people. The results showed that work loyalty is directly influenced by work incentives, morale, workload, and work stress. This study also found that morale is very influential on employee job loyalty. Based on these findings, it can be concluded that any changes that occur in Employee Loyalty are influenced by Work Incentives, Work Morale, Workload, and Work Stress. Therefore, Work Incentives, Work Spirit, Workload, Work Stress on Work Loyalty can be taken into consideration in making strategic planning for human resource development.
\end{abstract}

Keywords: Work Incentives, Work Spirit, Workload, Work Stress, Work Loyalty

\section{Pendahuluan}

Sumber daya manusia (SDM) merupakan faktor sentral dalam suatu organisasi. Apapun bentuk dan tujuannya, suatu organisasi didirikan berdasarkan visi untuk kepentingan bersama, dan dalam pelaksanaan misinya dikelola dan diurus oleh manusia. Tenaga kerja atau karyawan merupakan sumber yang paling berharga didalam organisasi. Tanpa adanya tenaga kerja atau karyawan yang berkualitas mustahil tujuan organisasi dapat tercapai dengan baik.

Organisasi dilakukan dalam suatu sistem yang terdiri daripada aktivitas-aktivitas yang dilakukan secara teratur dan berulang-ulang oleh sekelompok orang untuk mencapai tujuan bersama. Untuk mencapai tujuan tersebut, sebuah organisasi harus didukung oleh sumber-sumber daya yang berkualitas baik dari berwujud material, modal maupun manusia.

Insentif adalah suatu sarana memotivasi berupa materi, yang di berikan sebagai suatu perangsang ataupun pendorong dengan sengaja kepada para pekerja agar dalam diri mereka timbul semangat yang besar untuk meningkatkan produktivitas kerjanya dalam organisasi.

Semangat kerja adalah sikap mental dari individu atau kelompok yang menunjukkan kegairahan untuk melaksanakan pekerjaannya sehingga mendorong untuk mampu bekerjasama dan dapat menyelesaikan tugas tepat pada waktunya dengan rasa tanggung 
jawab terhadap pekerjaan yang dibebankan kepadanya. Untuk membahas tentang semangat kerja maka ada banyak para ahli memberikan.

Beban kerja adalah sekumpulan atau sejumlah kegiatan yang harus diselesaikan oleh suatu unit organisasi atau pemegang jabatan dalam jangka waktu tertentu.

Adapun untuk Pegawai Pemerintahan yang memiliki Kinerja baik, mereka akan mendapatkan perhatian yang serius dari atasan dan lembaganya serta atasan maupun lembaganya akan memberikan segala apapun yang menjadi kebutuhannya dalam bekerja setiap hari.

Berdasarkan latar belakang yang telah dikemukakan di atas, maka penulis tertarik untuk melakukan penelitian dengan judul "Pengaruh Pemberian Insentif, Semangat Kerja, Beban Kerja dan Stres Kerja Terhadap Loyalitas Pegawai Pada Kantor Kecamatan Batam Kota, Kota Batam"

\section{Rumusan Masalah}

Adapun rumusan masalah dalam penelitian ini adalah sebagai berikut: (1) Apakah Terdapat Pengaruh Pemberian Insentiif Terhadap Loyalitas? (2) Apakah Terdapat Pengaruh Semangat Kerja Terhadap Loyalitas Pegawai? (3) Apakah Terdapat Pengaruh Beban Kerja Terhadap Loyalitas Pegawai? (4) Apakah Terdapat Pengaruh Stres Kerja Terhadap Peningkatan Kinerja Pegawai? (5) Apakah Terdapat Pengaruh Pemberian Insentif, Semangat Kerja, Beban Kerja dan Stres Kerja Secara BersamaSama Terhadap Loyalitas Pegawai?

\section{Kajian Pustaka / Kajian Teori Pengertian Loyalitas Kerja}

Menurut Siagian (2010), loyalitas adalah suatu kecenderungan karyawan untuk tidak pindah ke perusahaan lain sebab loyalitas dapat mempengaruhi pada kenyamanan karyawan untuk bekerja pada suatu perusahaan.

Hasibuan (2012) mengemukakan bahwa loyalitas atau kesetiaan merupakan salah satu unsur yang digunakan dalam penilaian karyawan yang mencakup kesetiaan terhadap pekerjaannya, jabatannya dan organisasi. Kesetiaannya ini dicerminkan oleh kesediaan karyawan menjaga dan membela organisasi di dalam maupun di luar pekerjaan dari rongrongan orang yang tidak bertanggung jawab.

Lebih jauh lagi dijelaskan oleh Nitisemito (2002) bahwa loyalitas merupakan suatu sikap mental karyawan yang ditunjukkan kepada keberadaan perusahaan sehingga karyawan akan tetap bertahan dalam perusahaan, meskipun perusahaan tersebut maju atau mundur.

Berdasarkan uraian beberapa pengertian di atas, dapat disimpulkan bahwa loyalitas atau kesetiaan merupakan salah satu unsur penilaian untuk mengidentifikasi kesetiaan karyawan terhadap pekerjaannya, jabatannya dan organisasi yang mana dicerminkan oleh kesediaan karyawan menjaga dan membela organisasi di dalam maupun di luar pekerjaan dari rongrongan orang yang tidak bertanggung jawab.

\section{Pengertian Insentif Kerja}

Insentif adalah suatu sarana memotivasi berupa materi, yang diberikan sebagai suatu perangsang ataupun pendorong dengan sengaja kepada para pekerja agar dalam diri mereka timbul semangat yang besar untuk meningkatkan produktivitas kerjanya dalam organisasi (Gorda, 2008:141). 
Sedangkan Manullang (2005:147) menyatakan, Insetif merupakan sarana motivasi/sarana yang menimbulkan dorongan.

Menurut Samsudin (2006:194) mendefinisikan insentif adalah "pemberian upah atau gaji yang berbeda, bukan didasarkan pada evaluasi jabatan, namun karena adanya perbedaan prestasi kerja".

Berdasarkan uraian pendapat-pendapat para ahli diatas dapat penulis simpulkan, bahwa insentif merupakan salah satu bentuk rangsangan atau motivasi yang sengaja diberikan oleh perusahaan atau lembaga kepada karyawan, sehingga mendorong semagat kerja para karyawan agar mereka dapat bekerja lebih produktif lagi, dan mencapai tingkat kinerja yang lebih tinggi prestasinya dalam mencapai tujuan perusahaan atau lembaga.

\section{Pengertian Semangat Kerja}

Semangat kerja sebagai setiap kesediaan perasaan yang memungkinkan seseorang bekerja untuk menghasilkan kerja lebih banyak dan lebih baik. (Hariyanti, 2005: 155). Sedangkan Menurut Hasibuan (2009: 94), Semangat kerja adalah keinginan dan kesungguhan seseorang mengerjakan pekerjaannya dengan baik serta berdisiplin untuk mencapai prestasi kerja yang maksimal.

Sedangkan Siswanto (2006, p.35), mendefinisikan semangat kerja sebagai keadaan psikologis seseorang. Berdasarkan uraian diatas dapat disimpulkan bahwa Semangat kerja pegawai lebih dari sekedar keanggotaan formal, karena meliputi sikap menyukai organisasi dan kesediaan untuk mengusahakan tingkat upaya yang tinggi bagi kepentingan organisasi demi pencapaian tujuan.

\section{Pengertian Beban Kerja}

Beban kerja menurut Meshkati dalam Astianto dan Suprihhadi (2014) dapat didefinisikan sebagai suatu perbedaan antara kapasitas atau kemampuan pekerja dengan tuntutan pekerjaan yang harus dihadapi.

Menurut Moekijat (2010, p.28) beban kerja adalah volume dari hasil kerja atau catatan tentang hasil pekerjaan yang dapat menunjukan volume yang dihasilkan oleh sejumlah pegawai dalam suatu bagian tertentu.

Herrianto (2010) menyatakan bahwa beban kerja adalah sejumlah kegiatan yang harus diselesaikan oleh seseorang ataupun sekelompok orang, selama periode waktu tertentu dalam keadaan normal.

Dapat disimpulkan bahwa beban kerja terlalu sedikit, karena tenaga kerja tidak diberi peluang untuk menggunakan keterampilan yang diperolehnya atau untuk mengembangkan kecakapan potensinya secara penuh

\section{Pengertian Stres Kerja}

Menurut Robbins (2008) stress adalah suatu kondisi dinamik yang didalamnya seorang individu di konfrotasikan dengan suatu peluang, kendala, atau tuntutan yang dikaitkan dengan apa yang sangat diinginkan dan hasilnya di persepsikan sebagai tidak pasti dan penting.

Sedangkan menurut Hasibuan (2010) stress adalah suatu kondisi ketegangan yang mempengaruhi emosi, proses pikir, dan kondisi seseorang. Orang-orang yang mengalami stress menjadi nerveous dan merasakan kekhawatiran kronis.

Sebagai hasilnya, pada diri karyawan berkembang berbagai macam gejala stress yang dapat mengganggu pelaksanaan kerja mereka (Rivai, 2004). 
Stress dalam pekerjaan dapat dicegah timbulnya dan dapat dihadapi tanpa memperoleh dampaknya yang negatif.

\section{Kerangka Pemikiran}

Variabel yang di pergunakan dalam penelitian ini adalah variabel Insentif Kerja, Semangat Kerja, Beban Kerja Dan Sters Kerja sebagai variabel bebas, sedangkan variabel dependennya adalah variabel Loyalitas Kerja Pegawai. Hubungan antara variabel secara skematik dapat dilihat pada gambar berikut ini:

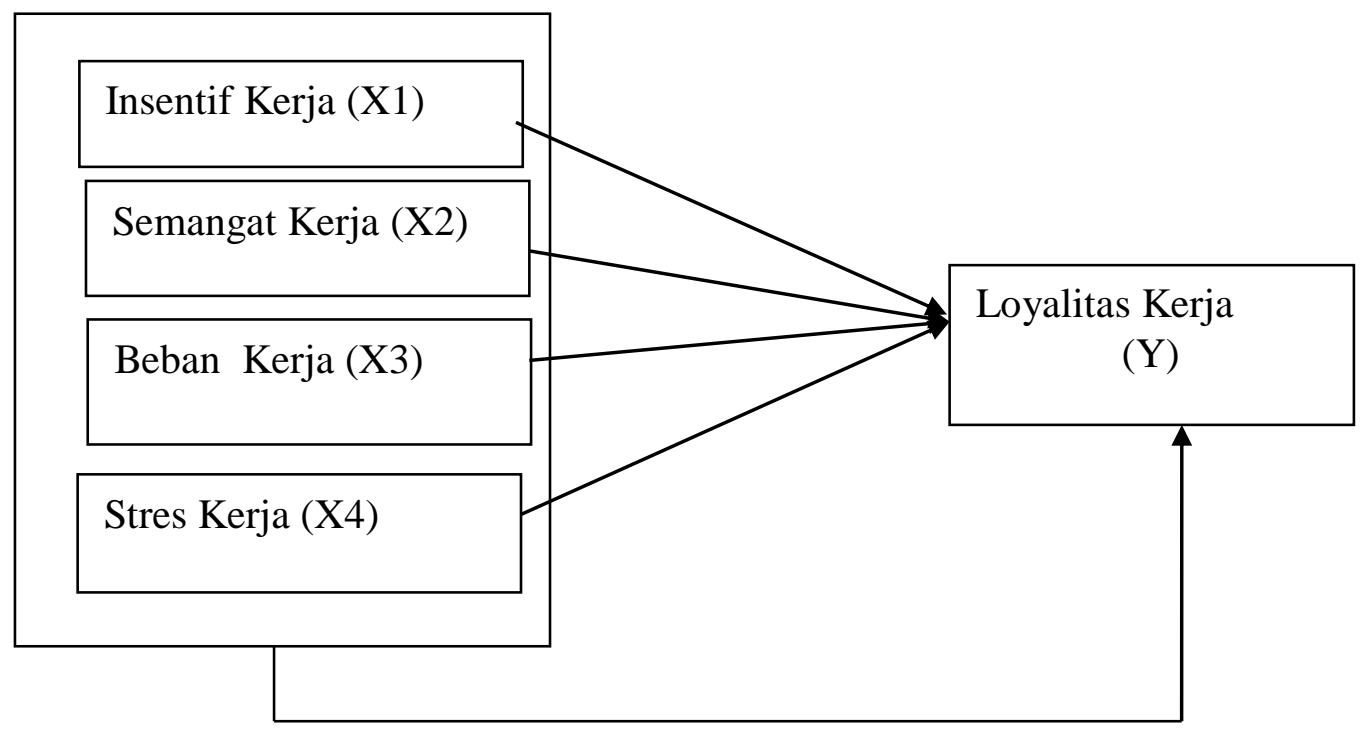

Gambar Kerangka Penelitian

\section{Hipotesis Penelitian}

Berdasarkan latar belakang masalah, landasan teoritis, tujuan penelitian dan serta melihat kondisi obyektif Pada Kantor Kecamatan Batam Kota, Kota Batam, maka penulis menyusun suatu dugaan sementara atau hipotesa bagi penelitian ini sebagai berikut : (1) Terdapat Pengaruh Insentif Kerja Terhadap Loyalitas Pegawai Pada Kantor Kecamatan Batam Kota, Kota Batam. (2) Terdapat Pengaruh Semangat Kerja Terhadap Loyalitas Pegawai Pada Kantor Kecamatan Batam Kota, Kota Batam. (3) Terdapat Pengaruh Beban Kerja Terhadap Loyalitas Pegawai Pada Kantor Kecamatan Batam Kota, Kota Batam. (4) Terdapat Pengaruh Stres Kerja Terhadap Loyalitas Pegawai Pada Kantor Kecamatan Batam Kota, Kota Batam. (5) Terdapat Pengaruh Insentif Kerja, Semangat Kerja, Beban Kerja Dan Stres Kerja Secara Bersama-Sama Terhadap Loyalitas Pegawai Pada Kantor Kecamatan Batam Kota, Kota Batam

\section{Metode Penelitian}

\section{Jenis dan Sumber Data}

Untuk melakukan penelitian, tentu diperlukan sejumlah data-data dan untuk memperolehnya dikelompokkan menjadi dua jenis: Data Primer, yaitu data yang penulis peroleh langsung dari obyek melalui penelitian atau pengamatan langsung terhadap masalah yang diteliti, yaitu melalui wawancara dengan Pegawai Pada Kantor Kecamatan Batam Kota, Kota Batam yang dikumpulkan melalui daftar pertanyaan 
yang belum diolah untuk tujuan tertentu, baik data - data yang telah dipersiapkan. Penelitian ini dilakukan dari Bulan Februari sampai dengan bulan Maret 2021

\section{Metode Pengumpulan Data}

Untuk melakukan penelitian tentu diperlukan sejumlah data dan untuk memperoleh data harus ada alat atau instrumennya. Dalam rangka mendapatkan datadata yang sesuai dengan kebutuhan dalam analisa, maka perlu dilakukan kegiatan pengumpulan data. Dalam kegiatan ini penulis mencoba mengumpulkan data dengan empat cara, yaitu: Interview (wawancara); Wawancara dilakukan terutama untuk memperoleh data-data primer. Untuk lebih intensifnya penggunaan metode interview ini, maka di dalam programnya juga dilengkapi dengan menggunakan beberapa daftar pertanyaan yang berkaitan langsung dengan masalah yang menjadi objek penelitian ini. Adapun data yang dapat dikumpulkan dengan cara ini dapat meliputi kegiatan Pegawai Pada Kantor Kecamatan Batam Kota, Kota Batam. Teknik Penyebaran Kuesioner; Yaitu dengan membagi - bagikan kuesioner kepada Pegawai yang menjadi responden penelitian ini, kemudian memberikan kesempatan bagi responden untuk mengisi kuesioner selama beberapa hari serta menghimbau agar dapat mengisi formulir isian secara obyektif.

\section{Populasi dan Sample}

Populasi dalam penelitian ini adalah Semua Pegawai Tetap dan honorer Pada Kantor Kecamatan Batam Kota, Kota Batam. Populasi yang ada pada tahun 2020 yaitu berjumlah 70 orang pegawai, maka penulis dalam menentukan sampel menggunakan Sampling jenuh, dimana semua jumlah populasi yang ada penulis menjadikannya responden dalam penelitian ini. Total responden dalam penelitian ini adalah sebanyak 70 orang responden.

\section{Analisis Regresi Berganda}

Dalam menganalisa data yang telah dikumpulkan serta pembuktian hipotesis, maka digunakan Analisa Deskriptif, yaitu menganalisa data yang diperoleh di lapangan berdasarkan kenyataan dan menghubungkannya dengan teori - teori yang ada. Disamping itu, penulis akan melakukan tabulasi berdasarkan data - data dari jawaban responden terpilih untuk mengetahui secara lebih jelas lagi apakah Insentif Kerjaq, Semangat Kerja, Beban Kerja Dan Stres Kerja Berpengaruh Terhadap Loyalitas Kerja Pegawai Pada Kantor Kecamatan Batam Kota, Kota Batam. Selanjutnya untuk mengetahui pengaruh hubungan antara variabel Insentif Kerja, Semangat Kerja, Beban Kerja dan Stres Kerja maka digunakanlah rumus statistik Regresi dan Korelasi Berganda. Adapun untuk penyelesaian pengolahan datanya, penulis menggunakan software SPSS Versi 17.0

\section{Hasil dan Pembahasan}

\section{Uji Validitas dan Reliabilitas}

Dari semua pertanyaan yang diajukan oleh peneliti, yaitu sebanyak 25 pertanyaan dari 4 variabel independen dan 1 variabel dependen, serta masing-masing variabel dengan 5 pertanyaan, diperoleh hasil bahwa semua pertanyaan kuesioner dinyatakan VALID.

Dari semua pertanyaan yang diajukan oleh peneliti, yaitu sebanyak 25 pertanyaan dari 4 variabel independen dan 1 variabel dependen, masing-masing dengan 
5 pertanyaan, diperoleh hasil bahwa semua pertanyaan kuesioner dinyatakan RELIABEL.

\section{Analisa Pengaruh Insentif Kerja ( $\left.\mathbf{X}_{1}\right)$ Terhadap Loyalitas Kerja Pegawai (Y)}

Variabel independen pertama yang penulis analisa dalam penelitian ini adalah Insentf Kerja (X1), dimana dalam hal ini akan dianalisa dan dilakukan pembuktian hipotesa, apakah variabel Insentif Kerja $\left(\mathrm{X}_{1}\right)$ berpengaruh terhadap Loyalitas Kerja (Y) Pegawai Pada Camat Batam Kota, Batam.

\section{Model Summary}

\begin{tabular}{rrrrr}
\hline Model & $\mathrm{R}$ & $\mathrm{R}$ Square & Adjusted R Square & Std. Error of the Estimate \\
1 & $.696^{\mathrm{a}}$ & .534 & .628 & 1.263 \\
\hline
\end{tabular}

a. Predictors: (Constant), Insentif Kerja

Angka R Square yang merupakan angka korelasi yang dikuadratkan atau $0,696^{2}$ ialah sebesar 0,534. Angka R Square disebut juga sebagai Koefisien Determinasi. Besarnya angka koefisien determinasi 0,534 atau sama dengan 53,40\%. Angka tersebut berarti hanya sebesar 53,40\% Loyalitas Kerja Pegawai dapat dijelaskan dengan menggunakan variabel Insentif Kerja Pegawai. Sedangkan sisanya, yaitu 46,60\% (100\% - 53,40\%) harus dijelaskan oleh faktor-faktor penyebab lainnya. Untuk diketahui, besarnya $\mathrm{R}$ Square berkisar antara 0 hingga 1 yang berarti semakin kecil besarnya $\mathrm{R}$ Square, maka hubungan kedua variabel semakin lemah. Sebaliknya, jika R Square semakin mendekati 1, maka hubungan kedua variabel semakin kuat.

\section{Coefficients $^{\mathrm{a}}$}

\begin{tabular}{|c|c|c|c|c|c|c|}
\hline & \multirow{3}{*}{$\begin{array}{r}\text { Model } \\
\text { (Constant) }\end{array}$} & \multicolumn{5}{|c|}{$\begin{array}{r}\text { Standardized } \\
\text { Coefficients }\end{array}$} \\
\hline & & $B$ & Std. Error & Beta & $\mathrm{t}$ & Sig. \\
\hline 1 & & 5.288 & 1.666 & & 2.575 & .012 \\
\hline & Insentif Kerja & .718 & .075 & .796 & 7.850 & .000 \\
\hline
\end{tabular}

a. Dependent Variable: Loyalitas Kerja

Karena $\mathrm{t}$ hitung $(7,850)>\mathrm{t}$ tabel $(1,667)$, maka Ho ditolak dan $\mathrm{H}_{1}$ diterima, artinya ; Koefisien regresi signifikan atau variabel Insentif Kerja berpengaruh terhadap Loyalitas Kerja Pegawai Pada Kantor Camat Batam Kota.

\section{Analisa Pengaruh Semangat Kerja $\left(\mathbf{X}_{2}\right)$ Terhadap Loyalitas Pegawai $(\mathbf{Y})$}

Variabel independen kedua yang penulis analisa adalah Semangat Kerja $\left(\mathrm{X}_{2}\right)$, dimana dalam hal ini akan dianalisa dan dilakukan pembuktian hipotesa, apakah faktor Semangat Kerja (X1) berpengaruh terhadap Loyalitas Kerja (Y) Pegawai Pada Kantor Camat Batam Kota, Batam.

\begin{tabular}{rrrrr}
\multicolumn{5}{c}{ Model Summary } \\
\hline Model & $\mathrm{R}$ & $\mathrm{R}$ Square & Adjusted R Square & Std. Error of the Estimate \\
1 & $.796^{\mathrm{a}}$ & .634 & .628 & 1.263 \\
\hline
\end{tabular}

a. Predictors: (Constant), Semangat Kerja

Angka R Square (angka korelasi yang dikuadratkan atau 0,796 2 sebesar 0,634. Angka R Square disebut juga sebagai Koefisien Determinasi. Besarnya angka koefisien determinasi 0,634 atau sama dengan 63,40 \%. Angka tersebut berarti hanya sebesar 
63,40 \% Loyalitas Kerja Pegawai yang terjadi dapat dijelaskan dengan menggunakan variabel Semangat Kerja. Sedangkan sisanya, yaitu $25 \%(100 \%-75 \%)$ harus dijelaskan oleh faktor-faktor penyebab lainnya. Untuk diketahui, besarnya $\mathrm{R}$ Square berkisar antara 0 hingga 1 yang berarti semakin kecil besarnya $\mathrm{R}$ Square, maka hubungan kedua variabel semakin lemah. Sebaliknya, jika R Square semakin mendekati 1, maka hubungan kedua variabel semakin kuat.

\begin{tabular}{|c|c|c|c|c|c|c|}
\hline \multicolumn{7}{|c|}{ Coefficients $^{\mathrm{a}}$} \\
\hline & & Unstandardi & Oefficients & $\begin{array}{r}\text { Standardized } \\
\text { Coefficients }\end{array}$ & & \\
\hline \multirow{3}{*}{1} & Model & B & Std. Error & Beta & $\mathrm{t}$ & Sig. \\
\hline & (Constant) & 4.288 & 1.666 & & 2.575 & .012 \\
\hline & Semangat Kerja & .818 & .075 & .796 & 10.850 & .000 \\
\hline
\end{tabular}

a. Dependent Variable: Loyalitas Kerja

Karena t hitung $(14,290)>\mathrm{t}$ tabel $(1,667)$, maka Ho ditolak dan $\mathrm{H}_{1}$ diterima, artinya ; Koefisien regresi signifikan atau variabel Semangat Kerja berpengaruh terhadap variabel Loyalitas Kerja Pegawai.

\section{Analisa Pengaruh Beban Kerja $\left(\mathbf{X}_{3}\right)$ Terhadap Loyalitas Kerja Pegawai (Y)}

Variabel bebas ketiga yang penulis analisa adalah variabel Beban Kerja $\left(\mathrm{X}_{3}\right)$, dimana dalam hal ini akan dianalisa dan dilakukan pembuktian hipotesa, apakah Beban Kerja (X3) berpengaruh terhadap Loyalitas Kerja (Y) Pegawai Pada Kantor Camat Batam Kota, Batam.

\begin{tabular}{rrrrr}
\multicolumn{5}{c}{ Model Summary } \\
\hline Model & $\mathrm{R}$ & R Square & Adjusted R Square & Std. Error of the Estimate \\
1 & $.866^{\mathrm{a}}$ & .750 & .747 & 1.043 \\
\hline
\end{tabular}

a. Predictors: (Constant), Beban Kerja

Angka R Square merupakan angka korelasi yang dikuadratkan atau $0,866^{2}$, yaitu sebesar 0,750. Angka R Square disebut juga sebagai Koefisien Determinasi. Besarnya angka koefisien determinasi 0,750 atau sama dengan 75,0\%. Angka tersebut berarti sebesar $75 \%$ Loyalitas Kerja Pegawai yang terjadi dapat dijelaskan dengan menggunakan variabel Beban Kerja Pegawai. Sedangkan sisanya, yaitu 25\% (100\% $75 \%$ ) harus dijelaskan oleh faktor-faktor penyebab lainnya. Untuk diketahui, besarnya $\mathrm{R}$ Square berkisar antara 0 hingga 1 yang berarti semakin kecil besarnya $\mathrm{R}$ Square, maka hubungan kedua variabel semakin lemah. Sebaliknya, jika R Square semakin mendekati 1, maka hubungan kedua variabel semakin kuat.

\begin{tabular}{|c|c|c|c|c|c|c|}
\hline \multicolumn{7}{|c|}{ Coefficients $^{\mathrm{a}}$} \\
\hline & & Unstandardiz & Doefficients & $\begin{array}{r}\text { Standardized } \\
\text { Coefficients }\end{array}$ & & \\
\hline \multirow{3}{*}{1} & Model & B & Std. Error & Beta & $\mathrm{t}$ & Sig. \\
\hline & (Constant) & 2.512 & 1.389 & & 1.808 & .075 \\
\hline & Beban Kerja & .885 & .062 & .866 & 14.290 & .000 \\
\hline
\end{tabular}

a. Dependent Variable: Loyalitas Kerja

Karena $\mathrm{t}$ hitung $(16,377)>\mathrm{t}$ tabel $(1,667)$, maka Ho ditolak dan $\mathrm{H}_{1}$ diterima, artinya; Koefisien regresi signifikan atau variabel Beban Kerja berpengaruh terhadap variabel Loyalitas Kerja Pegawai Pada Kantor Camat Batam Kota. 


\section{Analisa Pengaruh Stres Kerja $\left(\mathrm{X}_{4}\right)$ Terhadap Loyalitas Kerja Pegawai (Y)}

Variabel bebas ketiga yang penulis analisa adalah variabel Stres Kerja $\left(\mathrm{X}_{4}\right)$, dimana dalam hal ini akan dianalisa dan dilakukan pembuktian hipotesa, apakah Stres Kerja (X4) berpengaruh terhadap Loyalitas Kerja (Y) Pegawai Pada Kantor Camat Batam Kota, Batam.

\begin{tabular}{|c|c|c|c|c|}
\hline \multicolumn{5}{|c|}{ Model Summary } \\
\hline Model & $\mathrm{R}$ & R Square & Adjusted R Square & Std. Error of the Estimate \\
\hline 1 & $.893^{\mathrm{a}}$ & .798 & .795 & .939 \\
\hline
\end{tabular}

a. Predictors: (Constant), Stres Kerja

Angka R Square merupakan angka korelasi yang dikuadratkan atau $0,893^{2}$, yaitu sebesar 0,798. Angka R Square disebut juga sebagai Koefisien Determinasi. Besarnya angka koefisien determinasi 0,798 atau sama dengan 79,80\%. Angka tersebut berarti sebesar 79,80\% Loyalitas Kerja Pegawai yang terjadi dapat dijelaskan dengan menggunakan variabel Stres Kerja. Sedangkan sisanya, yaitu 20,20\% (100\% - 79,80\%) harus dijelaskan oleh faktor-faktor penyebab lainnya. Untuk diketahui, besarnya $\mathrm{R}$ Square berkisar antara 0 hingga 1 yang berarti semakin kecil besarnya $\mathrm{R}$ Square, maka hubungan kedua variabel semakin lemah. Sebaliknya, jika R Square semakin mendekati 1, maka hubungan kedua variabel semakin kuat.

\begin{tabular}{|c|c|c|c|c|c|c|}
\hline \multicolumn{7}{|c|}{ Coefficients $^{a}$} \\
\hline & & Unstandardiz & Coefficients & $\begin{array}{r}\text { Standardized } \\
\text { Coefficients }\end{array}$ & & \\
\hline \multirow{3}{*}{1} & Model & B & Std. Error & Beta & $t$ & Sig. \\
\hline & (Constant) & 2.223 & 1.230 & & 1.807 & .075 \\
\hline & Stres Kerja & .903 & .055 & .893 & 16.377 & .000 \\
\hline
\end{tabular}

a. Dependent Variable: Loyalitas Kerja

Karena $\mathrm{t}$ hitung $(16,377)>\mathrm{t}$ tabel $(1,667)$, maka Ho ditolak dan $\mathrm{H}_{1}$ diterima, artinya; Koefisien regresi signifikan atau variabel Stres Kerja berpengaruh terhadap variabel Kinerja Pegawai Pada Kantor Camat Batam Kota, Batam.

Analisa Korelasi Insentif Kerja $\left(\mathbf{X}_{1}\right)$, Semangat Kerja $\left(\mathbf{X}_{2}\right)$, Beban Kerja $\left(\mathbf{X}_{3}\right)$ dan Stres Kerja $\left(\mathbf{X}_{4}\right)$ Secara Simultan Terhadap Loyalitas Kerja Pegawai $(\mathbf{Y})$

Variabel analisa selanjutnya adalah secara bersama-sama Tingkat Insentif Kerja $\left(\mathrm{X}_{1}\right)$, Semangat Kerja $\left(\mathrm{X}_{2}\right)$, Beban Kerja $\left(\mathrm{X}_{3}\right)$ dan Stres Kerja $\left(\mathrm{X}_{4}\right)$ dimana dalam hal ini akan dianalisa dan dilakukan pembuktian hipotesa, apakah ke empat faktor tersebut secara bersamaan berpengaruh terhadap Loyalitas Kerja (Y) Pegawai Pada Kantor Camat Batam Kota, Batam.

Model Summary

\begin{tabular}{rrrrr}
\hline Model & $\mathrm{R}$ & $\mathrm{R}$ Square & Adjusted R Square & Std. Error of the Estimate \\
1 & $.920^{\mathrm{a}}$ & .846 & .839 & .832 \\
\hline
\end{tabular}

a. Predictors: (Constant), Stres Kerja, Semangat Kerja, Bebang Kerja, Insentif Kerja

Angka R Square (angka korelasi yang dikuadratkan atau $0,920^{2}$ ) sebesar 0,846 . Angka R Square disebut juga sebagai Koefisien Determinasi. Besarnya angka koefisien determinasi 0,846 atau sama dengan 84,60\%. Angka tersebut berarti sebesar 84,60\% Loyalitas Kerja Pegawai yang dapat dijelaskan dengan menggunakan variabel Insentif 
Kerja $\left(\mathrm{X}_{1}\right)$, Semangat Kerja $\left(\mathrm{X}_{2}\right)$, Beban Kerja $\left(\mathrm{X}_{3}\right)$ dan Stres Kerja $\left(\mathrm{X}_{4}\right)$. Sedangkan sisanya, yaitu $15,40 \%(100 \%-84,60 \%)$ harus dijelaskan oleh faktor-faktor penyebab lainnya. Untuk diketahui, besarnya R Square berkisar antara 0 hingga 1 yang berarti semakin kecil besarnya $\mathrm{R}$ Square, maka hubungan kedua variabel semakin lemah. Sebaliknya, jika R Square semakin mendekati 1, maka hubungan kedua variabel semakin kuat.

\begin{tabular}{rrrrrrr}
\multicolumn{1}{c}{ ANOVA $^{\mathrm{b}}$} & & & \\
\hline \multirow{2}{*}{1} & Model & Sum of Squares & df & Mean Square & F & Sig. \\
& Ression & 250.639 & 3 & 83.546 & 120.798 & $.000^{\mathrm{a}}$ \\
& Residual & 45.647 & 66 & .692 & & \\
& Total & 296.286 & 69 & & & \\
\hline
\end{tabular}

a. Predictors: (Constant), Stres Kerja, Semangat Kerja, Bebang Kerja, Insentif Kerja

b. Dependent Variable: Loyalitas Kerja

Uji Anova menghasilkan angka $\mathrm{F}_{\text {hitung }}$ sebesar 120,798 $>\mathrm{F}_{\text {tabel }} 2,74$ dengan tingkat signifikansi (angka probabilitas) sebesar 0,05. $\mathrm{F}$ hitung $>\mathrm{F}$ tabel maka $\mathrm{H}_{\mathrm{o}}$ ditolak dan $\mathrm{H}_{1}$ diterima. Maka koefisien regresi Insentif Kerja $\left(\mathrm{X}_{1}\right)$, Semangat Kerja $\left(\mathrm{X}_{2}\right)$, Beban Kerja $\left(\mathrm{X}_{3}\right)$ dan Stres Kerja $\left(\mathrm{X}_{4}\right)$ secara bersama-sama berpengaruh signifikan terhadap variabel Y (Loyalitas Kerja Pegawai)

\section{Kesimpulan}

Berdasarkan uraian pada bab terdahulu, maka secara umum dapat disimpulkan sebagai berikut: (1). Dalam pengujian hipotesa apakah variabel Insentif Kerja berpengaruh terhadap Loyalitas Kerja Pegawai, maka Karena t hitung $(7,850)>t$ tabel (1,667), maka Ho ditolak dan $\mathrm{H}_{1}$ diterima, artinya; Koefisien regresi signifikan atau variabel Insentif Kerja berpengaruh terhadap Loyalitas Kerja Pegawai Pada Kantor Camat Batam Kota, Batam. (2). Dalam pengujian hipotesa apakah variabel Semangat Kerja berpengaruh terhadap Loyalitas Kerja Pegawai Pada Kantor Camat Batam Kota, maka Karena $t$ hitung $(10,850)>\mathrm{t}$ tabel $(1,667)$, maka Ho ditolak dan $\mathrm{H}_{1}$ diterima, artinya; Koefisien regresi signifikan atau variabel Semangat Kerja berpengaruh terhadap variabel Loyalitas Kerja Pegawai. (3). Dalam pengujian hipotesa apakah variabel Beban Kerja Pegawai berpengaruh terhadap Loyalitas Kerja Pegawai Pada Kantor Camat Batam Kota, maka Karena $t$ hitung $(14,290)>t$ tabel $(1,667)$, maka Ho ditolak dan $\mathrm{H}_{1}$ diterima, artinya; Koefisien regresi signifikan atau variabel Beban Kerja berpengaruh terhadap variabel Loyalitas Kerja Pegawai. (4). Dalam pengujian hipotesa apakah variabel Stres Kerja berpengaruh terhadap Loyalitas Kerja Pegawai Pada Kantor Camat Batam Kota, Batam, maka Karena t hitung $(16,373)>\mathrm{t}$ tabel $(1,667)$, maka Ho ditolak dan $\mathrm{H}_{1}$ diterima, artinya; Koefisien regresi signifikan atau variabel Stres Kerja berpengaruh terhadap variabel Loyalitas Kerja Pegawai. (5). Dalam Pengujian hipotesa apakah variabel Insentif Kerja, Semangat Kerja, Beban Kerja dan Stres Kerja Pegawai secara simultan berpengaruh terhadap Loyalitas Kerja Pegawai Pada Kantor Camat Batam Kota, Batam. Uji Anova menghasilkan angka $F_{\text {hitung }}$ sebesar 120,798> $F_{\text {tabel }} 2,74$ dengan tingkat signifikansi (angka probabilitas) sebesar 0,05. F hitung $>\mathrm{F}$ tabel maka $\mathrm{H}_{\mathrm{o}}$ ditolak dan $\mathrm{H}_{1}$ diterima. Maka koefisien regresi Insentif Kerja $\left(\mathrm{X}_{1}\right)$, Semangat Kerja $\left(\mathrm{X}_{2}\right)$, Beban Kerja $\left(\mathrm{X}_{3}\right)$ dan Stres Kerja $\left(\mathrm{X}_{4}\right)$ secara bersama-sama berpengaruh signifikan terhadap variabel Loyalitas Kerja Pegawai (Y). 


\section{Saran - saran}

Saran - saran yang perlu penulis sampaikan kepada Pimpinan Kantor Camat Batam Kota, Batam adalah sebagai berikut: (1). Hendaknya pimpinan selalu memperhatikan bagaimana memberikan motivasi kerja kepada pegawai. Dengan memberikan motivasi, pimpinan ikut serta dalam memberikan sumbangsih kepada loyalitas kerja pegawai. (2). Penulis menyarankan agar dalam menempatkan pegawai, sebaiknya pimpinan menempatkan pegawai berdasarkan keahlian masing-masing pegawai. (3). Disarankan kepada Pimpinan Kantor Camat Batam Kota agar dapat memberikan dorongan semangat bekerja (supporting) kepada para pegawai setia hari. (4). Penulis menyarankan kepada pimpinan agar pendidikan dan pelatihan pegawai setiap tahun terus diadakan. (5) Penulis menyarankan kepada pimpinan agar fasilitas kerja pegawai yang mendukung pekerjaan pegawai.

\section{Daftar Pustaka}

Alex S Nitisemito, 2011, Manajemen Personalia (Manajemen Sumber. Daya Manusia), Edisi Kelima, Cetakan Keempat Belas, Ghalia.

Behavior: Hasibuan, Malayu Sp. 2012. Manajemen SDM. Edisi Revisi, Cetakan Ke Tigabelas. Jakarta: Bumi Aksara.

H.B. Siswanto. 2006. Pengantar Manajemen. Jakarta : Bumi Aksara

Ivancevich, Konopaske, dan Matteson, Organizational Behaviour and Management, New York: McGraw Hill Company, 2008t.

Rivai,Veithzal. 2004. Manajemen Sumber Daya Manusia Untuk Perusahaan. Jakarta: Grafindo.

Robbins, Stephen, P, Timothy A Judge, Organizational Behaviour: New Jersey: Pearson Education, Inc, 2011.

Kumorotomo, Wahyudi, Purwanto, Erwan Agus.2005.Aggaran Berbasis Kinerja, Konsep \& Aplikasinya. Yogyakarta: MAP UGM

Widodo. 2015. Manajemen Pengembangan Sumber Daya Manusia. Pustaka Pelajar. Yogjakarta.

Mangkunegara, A. A. Anwar Prabu. (2009). Manajemen Sumber Daya Manusia Perusahaan. Bandung: PT. Remaja Rosdakarya.

Moekijat, 2010, Manajemen Kepegawaian Dan Hubungan Dalam Perusahaan, Edisi Ketiga, Alumni Bandung.

Robbins, Stephen. P. 2006. Perilaku Organisasi (alih bahasa Drs. Benjamin Molan), Edisi Bahasa Indonesia, Klaten: PT INT AN SEJATI.

Sondang P. Siagian. 2010. Manajemen Sumber Daya Manusia, Bumi Aksara, Jakarta. Soekidjan. (2009). Manjaemen Sumber Daya Manusia. Jakarta: Bumi Aksara. Sugiyono, 2010. Metode Penelitian Pendidikan Pendekatan Kuantitatif, Kualitatif, dan $R \& D$. Bandung: Alfabete. 